\title{
Pathological response rate in hormone-positive breast cancer patients treated with neoadjuvant FEC and triweekly docetaxel: a case series
}

This article was published in the following Dove Press journal:

Breast Cancer: Targets and Therapy

28 August 2015

Number of times this article has been viewed

\author{
Takayoshi Kiba' \\ Nao Morii ${ }^{2,3}$ \\ Hirotoshi Takahashi ${ }^{2}$ \\ Shinji Ozaki² \\ Misao Atsumi ${ }^{4}$ \\ Fumi Masumoto ${ }^{4}$ \\ Hiroyasu Yamashiro ${ }^{2,3}$ \\ 'Division of Modern Medical \\ Technology, Institute for Clinical \\ Research, ${ }^{2}$ Department of Breast \\ Surgery, National Hospital \\ Organization Kure Medical Center \\ and Chugoku Cancer Center, Kure, \\ Japan; ${ }^{3}$ Department of Breast Surgery, \\ Tenri Hospital, Tenri, Nara, Japan; \\ ${ }^{4}$ Clinical Trial Management Office, \\ National Hospital Organization Kure \\ Medical Center and Chugoku Cancer \\ Center, Kure, Japan
}

\begin{abstract}
We recently reported that neoadjuvant 5-FU, epirubicin, and cyclophosphamide (FEC) followed by weekly paclitaxel and/or trastuzumab induced a high pathological complete response $(\mathrm{pCR})$ rate in hormone-negative patients. The present study examined the therapeutic efficacy of neoadjuvant FEC followed by triweekly docetaxel and/or trastuzumab in the treatment of hormone-positive patients. Between February 2012 and December 2013, 16 hormone-positive patients with local breast cancer (luminal A type: six patients; luminal B type: two patients; luminal HER2 type: eight patients) were included in the study. The histological type of the primary cancer was invasive ductal carcinoma in all patients. The cancer stages in the 16 women who received this regimen were stage I in five $(31.3 \%)$, IIA in four $(25.0 \%)$, IIB in five $(31.3 \%)$, IIIB in one $(6.3 \%)$, and IIIC in one $(6.3 \%)$. Regarding clinical TNM classification, five patients were T1N0M0, one was T1N1M0, three were T2N0M0, five were T2N1M0, one was T3N2M0, and one was T4N0M0. The pCR was evaluated using resected tissue after neoadjuvant chemotherapy according to the evaluation criteria of the Japanese Breast Cancer Society. Patients were classified into pathologic responders (grade 2: $50.0 \%$ of all patients: $2 / 6$ of luminal A type; 6/8 of Luminal HER2 type) and nonresponders (grades 0 and 1: $50.0 \%$ of all patients: $4 / 6$ of luminal A type; $2 / 2$ of luminal B type; $2 / 8$ of luminal HER2 type) according to the grade of the tumor. The pCR rate was $0 \%$. Hematologic and nonhematologic toxicity was reversible and manageable. This study demonstrated that neoadjuvant FEC followed by triweekly docetaxel and/or trastuzumab did induce a high pathologic response in luminal HER2 type, but not in luminal A and B types, and did not induce a high pCR rate in the hormone-positive patients.
\end{abstract}

Keywords: luminal type, surgery, therapeutic efficacy

\section{Introduction}

Neoadjuvant chemotherapy is one option of standard therapies in breast cancer. It has been shown that neoadjuvant chemotherapy and adjuvant chemotherapy result in the same survival rate. ${ }^{1}$ Taxane chemotherapy improved the breast cancer patient outcomes in the adjuvant setting. ${ }^{2}$ However, in some studies, the benefit was difficult to evaluate because because of biologically heterogeneous populations and other factors, compared with anthracycline control regimens. ${ }^{2}$ Docetaxel is used for treating patients with locally advanced or metastatic breast cancer and/or with unsuccessful anthracycline-based chemotherapy. ${ }^{3}$ The drug promotes tubulin polymerization and stabilizing microtubule assembly, and prevents physiological microtubule dynamics. ${ }^{3}$ Clinically, it inhibits the proliferation of breast cancer cells, but results in several adverse effects in normal cells. ${ }^{3}$
Correspondence: Takayoshi Kiba

Division of Modern Medical Technology, Institute for Clinical Research, Nationa Hospital Organization Kure Medical Center and Chugoku Cancer Center, 3-I, Aoyama-cho, Kure-shi, Hiroshima, 737-0023, Japan

$\mathrm{Tel}+8 \mathrm{I} 823223 \mathrm{III}$

Fax +8I 823210478

Email takkiba@hotmail.com 
The PACS 01 trial concluded that sequential adjuvant chemotherapy with 5-FU, epirubicin, and cyclophosphamide (FEC) followed by docetaxel significantly improved disease-free survival and overall survival in node-positive breast cancer patients. ${ }^{4}$ A pooled analysis of the PACS 01 and BCIRG 001 studies suggested that the proportional reduction in the risk of death due to taxanes was almost identical in women with no ER expression and in women whose tumor stained positively in $>85 \%$ of cancer cells. ${ }^{5}$ It is suggested that the addition of taxanes to anthracyclines seemed to overcome the relative chemorefractoriness of hormone receptorpositive tumors. Therefore, the taxanes should be considered a step forward in the adjuvant treatment of women with hormone receptor-positive breast cancer, at least in the groups with positive axillary lymph nodes. On the other hand, other studies reported that pathological complete response (pCR) rates of $6 \%-10 \%$ and up to $55 \%$ were observed in hormone receptor-positive and -negative patients, respectively. ${ }^{6,7}$ The results suggest that hormone-positive breast cancer is less sensitive to chemotherapy, and therefore, hormone receptor status is associated with achieving a pCR. Consistent with this, a previous study suggested that taxane-based therapy improved outcomes in hormone receptor-negative disease or HER2-positive disease, but that it may not show any benefit in hormone receptor-positive, HER2-negative disease. ${ }^{8}$

In the present study, between February 2012 and December 2013, FEC followed by triweekly docetaxel and/or trastuzumab was administered in 16 hormone-positive patients with local breast cancer (luminal A type: six patients; luminal B type: two patients; luminal HER2 type: eight patients). This study investigated the therapeutic efficacy of neoadjuvant FEC and triweekly docetaxel and/or trastuzumab.

\section{Patients and method}

\section{Ethics statement}

Only demographic data of patients were stored in the database in National Hospital Organization Kure Medical Center and Chugoku Cancer Center to enable retrieval of files manually based on patient identification numbers. All data were anonymously analysed without individual patient consent due to the retrospective nature of the study. The Review Board Ethics Committee waived the need for individual informed consent and approved the study (approval number 26-68, date March 6, 2015).

\section{Patients}

Between February 2012 and December 2013, 16 hormonepositive patients with local breast cancer (luminal A type: six patients; luminal B type: two patients: luminal HER2 type: eight patients) were included in the study. All patients had three or four cycles of FEC (fluorouracil $500 \mathrm{mg} / \mathrm{m}^{2}$, epirubicin $100 \mathrm{mg} / \mathrm{m}^{2}$, cyclophosphamide $500 \mathrm{mg} / \mathrm{m}^{2}$ once every 3 weeks) followed by three or four cycles of docetaxel (100 mg/m² once every 3 weeks) or three or four cycles of triweekly trastuzumab ( $8 \mathrm{mg} / \mathrm{kg}$ week $1 ; 6 \mathrm{mg} / \mathrm{kg} /$ every 3 weeks thereafter, if HER2-positive). The difference of number of treatment regimens was due to the therapeutic efficacy using diagnostic imaging during the treatment period. The mean age of the patients at the time of paclitaxel regimen administration was 50.5 years (range 23-68) (Table 1). The histological type of the primary cancer was invasive ductal

Table I Patient characteristics $(n=16)$

\begin{tabular}{|c|c|}
\hline Median age, years (range) & $50.5(23-68)$ \\
\hline \multicolumn{2}{|l|}{ Sex } \\
\hline Male/female & $0 / 16$ \\
\hline \multicolumn{2}{|l|}{ ECOG performance status, $\mathrm{n}(\%)$} \\
\hline 0 & $16(100)$ \\
\hline$\geq 1$ & $0(0)$ \\
\hline \multicolumn{2}{|l|}{ Molecular subtypes, n (\%) } \\
\hline Luminal A type & $6(37.5)$ \\
\hline Luminal B type & $2(12.5)$ \\
\hline Luminal HER2 type & $8(50.0)$ \\
\hline \multicolumn{2}{|l|}{ AJCC stage of recipients of this regimen, $n(\%)$} \\
\hline 1 & $5(3 \mid .3)$ \\
\hline IIA & $4(25.0)$ \\
\hline IIB & $5(3 \mid .3)$ \\
\hline IIIB & I (6.3) \\
\hline IIIC & I (6.3) \\
\hline \multicolumn{2}{|l|}{ TNM classification, $\mathrm{n}(\%)$} \\
\hline TINOMO & $5(3 \mid .3)$ \\
\hline TINIMO & I (6.3) \\
\hline T2NOMO & $3(18.8)$ \\
\hline T2NIM0 & $5(31.3)$ \\
\hline T3N2M0 & I (6.3) \\
\hline T4NOMO & $\mathrm{I}(6.3)$ \\
\hline \multicolumn{2}{|l|}{ Number of FEC regimens, $\mathrm{n}(\%)$} \\
\hline 3 & $4(25.0)$ \\
\hline 4 & $12(75.0)$ \\
\hline \multicolumn{2}{|l|}{ Number of triweekly docetaxel regimens, $\mathrm{n}(\%)$} \\
\hline 3 & $3(37.5)$ \\
\hline 4 & $5(62.5)$ \\
\hline \multicolumn{2}{|c|}{ Number of triweekly docetaxel plus trastuzumab regimens, $\mathrm{n}(\%)$} \\
\hline 3 & I (I2.5) \\
\hline 4 & $7(87.5)$ \\
\hline \multicolumn{2}{|c|}{ Pathological responses of the tumor and dissected lymph nodes, $n(\%)$} \\
\hline Grade 0 & $2(12.5)$ \\
\hline Grade la & $0(0)$ \\
\hline Grade Ib & $6(37.5)$ \\
\hline Grade 2a & $6(37.5)$ \\
\hline Grade $2 b$ & $2(12.5)$ \\
\hline Grade 3 (pathological complete response) & $0(0)$ \\
\hline
\end{tabular}

Abbreviations: ECOG, Eastern Cooperative Oncology Group; AJCC, American Joint Committee on Cancer; FEC, 5-FU, epirubicin, and cyclophosphamide. 
carcinoma in all patients. The cancer stages in the 16 women who received this regimen were stage I in five (31.3\%), IIA in four $(25.0 \%)$, IIB in five (31.3\%), IIIB in one (6.3\%), and IIIC in one $(6.3 \%)$ women. Regarding clinical TNM classification, five patients were T1N0M0, one was T1N1M0, three were T2N0M0, five were T2N1M0, one was T3N2M0, and one was T4N0M0. Concomitant medication that did not interfere with the evaluation of FEC and paclitaxel could be given at the discretion of the investigator, including antiemetics, antidiarrheal therapy, corticosteroids, and antihistamines. Granulocyte colony-stimulating factor was allowed according to the American Society of Clinical Oncology guidelines and standard practice, including prophylactic use of growth factors. Other antitumor therapies were not allowed.

\section{Pathology assessment}

Pretreatment estrogen (ER) and progesterone receptor status were assessed by immunohistochemistry, and HER2 status was assessed by either fluorescent in situ hybridization or a validated immunohistochemistry method as previously described. ${ }^{9-11}$ Patients with HER2-receptor overexpression at the 3+ level (PATHWAY ${ }^{\circledR}$ HER2, clone 4B5; Ventana Medical Systems Inc., Tucson, AZ, USA) were immediately eligible for inclusion. pCR was defined as the absence of invasive carcinoma both in the breast and the axilla, regardless of the presence of carcinoma in situ. ${ }^{9}$ Primary tumor pCR was defined as absence of invasive carcinoma in the breast. ${ }^{9}$ When immunostaining was observed in more than $1 \%$ of tumor nuclei, the tumor was considered to be positive for the ER or progesterone receptors. ${ }^{11,12}$ Breast cancers were classified into five subtypes as previously described. ${ }^{11,12}$ Pathological responses of the tumor and dissected lymph nodes were classified according to the evaluation criteria of the Japanese Breast Cancer Society ${ }^{13}$ using a five-histological-grade scale (grades 0, 1a, 1b, 2, and 3 ) as previously described. ${ }^{11,14}$

\section{Results}

The pathological response was evaluated using resected tissue after neoadjuvant chemotherapy. Of the tumors investigated, $12.5 \%$ (2/16: $1 / 6$ of luminal A type; $1 / 2$ of luminal B type) were histological response grade $0,37.5 \%$ (6/16: $3 / 6$ of luminal A type; $1 / 2$ of luminal B type; $2 / 8$ of luminal HER2 type) were grade $1 b, 37.5 \%$ (6/16: 2/6 of luminal A type; $4 / 8$ of luminal HER2 type) were grade $2 \mathrm{a}$, and $12.5 \%$ (2/16: $2 / 8$ of luminal HER2 type) were grade $2 \mathrm{~b}$. Patients were classified into pathologic responders (grade 2: $50.0 \%$ of all patients: $2 / 6$ of luminal A type; $6 / 8$ of luminal HER2 type) and nonresponders (grades
0 and 1: $50.0 \%$ of all patients: $4 / 6$ of luminal A type; $2 / 2$ of luminal B type; 2/8 of luminal HER2 type) according to the grade of the tumor. The $\mathrm{pCR}$ rate was $0 \%$. There was a significant difference in pathological response detected between the docetaxel and docetaxel/trastuzumab regimen $(P=0.046$, chi-square tests). However, the status of tumor size or stage classification did not affect the pCR statistically.

All 16 patients were evaluated for toxicity using the Common Terminology Criteria for Adverse Events (CTCAE) version 4.0 (http://ctep.cancer.gov/protocolDevelopment/ electronic applications/ctc.htm\#ctc 40). Hematologic toxicity was reversible and manageable. In FEC regimen, patients reported grade 3 anemias (18.8\%) and grade 4 neutropenia (68.8\%) (Table 2). Although grade 4 neutropenia occurred, the patients were treated with granulocyte colony-stimulating factors. The grade $3 / 4$ nonhematologic toxicities were nausea $(25.0 \%)$, vomiting $(12.5 \%)$, and fatigue $(6.3 \%)$. Also, no treatment-related deaths were noted. Eighty-seven point five percent of patients on either the docetaxel or docetaxel/ trastuzumab regimen reported grade 4 neutropenia $(87.5 \%)$ (Table 3$)$. The grade $3 / 4$ nonhematologic toxicities were nausea $(12.5 \%)$, appetite loss $(12.5 \%)$, fatigue $(6.3 \%)$, stomatitis $(6.3 \%)$, and hand-foot skin reaction $(6.3 \%)$. No treatment-related deaths were noted. Because these toxicities were mild, the dose omission of FEC or docetaxel and/ or trastuzumab combination therapy was rare, and the study achieved favorable compliance.

Table 2 All adverse events of FEC $(\mathrm{N}=16)$

\begin{tabular}{|c|c|c|c|c|c|c|c|c|}
\hline \multirow{2}{*}{$\begin{array}{l}\text { Adverse event } \\
\text { of FEC }\end{array}$} & \multicolumn{2}{|c|}{ Grade I } & \multicolumn{2}{|c|}{ Grade 2} & \multicolumn{2}{|c|}{ Grade 3} & \multicolumn{2}{|c|}{ Grade 4} \\
\hline & $\mathbf{N}$ & $\%$ & $\mathbf{N}$ & $\%$ & $\mathbf{N}$ & $\%$ & $\mathbf{N}$ & $\%$ \\
\hline Anemia & 7 & 43.8 & 2 & 12.5 & 3 & 18.8 & 0 & 0 \\
\hline Neutropenia & 0 & 0 & I & 6.3 & 4 & 25.0 & II & 68.8 \\
\hline Nausea & 4 & 25.0 & 6 & 37.5 & 4 & 25.0 & 0 & 0 \\
\hline Vomiting & I & 6.3 & 0 & 0 & 2 & 12.5 & 0 & 0 \\
\hline Fatigue & 14 & 87.5 & 0 & 0 & I & 6.3 & 0 & 0 \\
\hline Palpitations & I & 6.3 & 0 & 0 & 0 & 0 & 0 & 0 \\
\hline Dyspnea & 1 & 6.3 & 0 & 0 & 0 & 0 & 0 & 0 \\
\hline Myalgia & 3 & 18.8 & 0 & 0 & 0 & 0 & 0 & 0 \\
\hline Sore throat & 3 & 18.8 & 0 & 0 & 0 & 0 & 0 & 0 \\
\hline Headache & 5 & 31.3 & 0 & 0 & 0 & 0 & 0 & 0 \\
\hline Lumbago & 1 & 6.3 & 0 & 0 & 0 & 0 & 0 & 0 \\
\hline Insomnia & I & 6.3 & 0 & 0 & 0 & 0 & 0 & 0 \\
\hline Appetite loss & 9 & 56.3 & 0 & 0 & 0 & 0 & 0 & 0 \\
\hline Stomatitis & 5 & 31.3 & 0 & 0 & 0 & 0 & 0 & 0 \\
\hline Abdominal pain & $\mathrm{I}$ & 6.3 & 0 & 0 & 0 & 0 & 0 & 0 \\
\hline Dysgeusia & 2 & 12.5 & 0 & 0 & 0 & 0 & 0 & 0 \\
\hline Diarrhea & 3 & 18.8 & I & 6.3 & 0 & 0 & 0 & 0 \\
\hline Constipation & 8 & 50.0 & 0 & 0 & 0 & 0 & 0 & 0 \\
\hline Fever & 3 & 18.8 & 0 & 0 & 0 & 0 & 0 & 0 \\
\hline Dizziness & 2 & 12.5 & 0 & 0 & 0 & 0 & 0 & 0 \\
\hline
\end{tabular}

Abbreviation: FEC, 5-FU, epirubicin, and cyclophosphamide. 
Table 3 All adverse events of docetaxel alone $(\mathrm{N}=8)$ and docetaxel plus trastuzumab $(\mathrm{N}=8)$

\begin{tabular}{|c|c|c|c|c|c|c|c|c|}
\hline & \multicolumn{2}{|c|}{ Grade I } & \multicolumn{2}{|c|}{ Grade 2} & \multicolumn{2}{|c|}{ Grade 3} & \multicolumn{2}{|c|}{ Grade 4} \\
\hline & $\mathbf{N}$ & $\%$ & $\mathbf{N}$ & $\%$ & $\mathbf{N}$ & $\%$ & $\mathbf{N}$ & $\%$ \\
\hline \multicolumn{9}{|c|}{ Adverse event of docetaxel alone } \\
\hline Anemia & 3 & 37.5 & 2 & 25.0 & 0 & 0 & 0 & 0 \\
\hline Neutropenia & 0 & 0 & 1 & 12.5 & 0 & 0 & 7 & 87.5 \\
\hline Nausea & I & 12.5 & 2 & 25.0 & 2 & 25.0 & 0 & 0 \\
\hline Fatigue & 3 & 37.5 & 3 & 37.5 & I & 12.5 & 0 & 0 \\
\hline Fever & 0 & 0 & 0 & 0 & 0 & 0 & 0 & 0 \\
\hline Myalgia & 1 & 12.5 & 0 & 0 & 0 & 0 & 0 & 0 \\
\hline Lumbago & 1 & 12.5 & 0 & 0 & 0 & 0 & 0 & 0 \\
\hline Joint pain & 3 & 37.5 & 0 & 0 & 0 & 0 & 0 & 0 \\
\hline Leg pain & 0 & 0 & 0 & 0 & 0 & 0 & 0 & 0 \\
\hline Insomnia & 2 & 25.0 & 0 & 0 & 0 & 0 & 0 & 0 \\
\hline Peripheral neuropathy & I & 12.5 & I & 12.5 & 0 & 0 & 0 & 0 \\
\hline Appetite loss & 2 & 25.0 & 0 & 0 & 2 & 25.0 & 0 & 0 \\
\hline Dyspepsia & 2 & 25.0 & 0 & 0 & 0 & 0 & 0 & 0 \\
\hline Stomatitis & 0 & 0 & 0 & 0 & 0 & 0 & 0 & 0 \\
\hline Dysgeusia & 2 & 25.0 & I & 12.5 & 0 & 0 & 0 & 0 \\
\hline Diarrhea & 4 & 50.0 & 0 & 0 & 0 & 0 & 0 & 0 \\
\hline Constipation & 2 & 25.0 & 0 & 0 & 0 & 0 & 0 & 0 \\
\hline Dyspnea & I & 12.5 & 0 & 0 & 0 & 0 & 0 & 0 \\
\hline Cough & 4 & 50.0 & 0 & 0 & 0 & 0 & 0 & 0 \\
\hline Hand-foot skin reaction & 3 & 37.5 & 0 & 0 & 0 & 0 & 0 & 0 \\
\hline Pruritus & 0 & 0 & 0 & 0 & 0 & 0 & 0 & 0 \\
\hline Rash & $\mathrm{I}$ & 12.5 & 0 & 0 & 0 & 0 & 0 & 0 \\
\hline Face edema & 1 & 12.5 & 0 & 0 & 0 & 0 & 0 & 0 \\
\hline Limb edema & I & 12.5 & 0 & 0 & 0 & 0 & 0 & 0 \\
\hline \multicolumn{9}{|c|}{ Adverse event of docetaxel and trastuzumab } \\
\hline Anemia & I & 12.5 & 6 & 75.0 & 0 & 0 & 0 & 0 \\
\hline Neutropenia & 0 & 0 & I & 12.5 & 0 & 0 & 7 & 87.5 \\
\hline Nausea & 2 & 25.0 & 0 & 0 & 0 & 0 & 0 & 0 \\
\hline Fatigue & 4 & 50.0 & 3 & 37.5 & 0 & 0 & 0 & 0 \\
\hline Fever & 1 & 12.5 & 0 & 0 & 0 & 0 & 0 & 0 \\
\hline Myalgia & 1 & 12.5 & 0 & 0 & 0 & 0 & 0 & 0 \\
\hline Lumbago & 0 & 0 & 0 & 0 & 0 & 0 & 0 & 0 \\
\hline Joint pain & 0 & 0 & 0 & 0 & 0 & 0 & 0 & 0 \\
\hline Leg pain & I & 12.5 & 0 & 0 & 0 & 0 & 0 & 0 \\
\hline Insomnia & 0 & 0 & 0 & 0 & 0 & 0 & 0 & 0 \\
\hline Peripheral neuropathy & 2 & 25.0 & 0 & 0 & 0 & 0 & 0 & 0 \\
\hline Appetite loss & I & 12.5 & 0 & 0 & 0 & 0 & 0 & 0 \\
\hline Dyspepsia & I & 12.5 & 0 & 0 & 0 & 0 & 0 & 0 \\
\hline Stomatitis & I & 12.5 & 1 & 12.5 & I & 12.5 & 0 & 0 \\
\hline Dysgeusia & 2 & 25.0 & 0 & 0 & 0 & 0 & 0 & 0 \\
\hline Diarrhea & 7 & 87.5 & 0 & 0 & 0 & 0 & 0 & 0 \\
\hline Constipation & 2 & 25.0 & 0 & 0 & 0 & 0 & 0 & 0 \\
\hline Dyspnea & 0 & 0 & 0 & 0 & 0 & 0 & 0 & 0 \\
\hline Cough & 3 & 37.5 & 1 & 12.5 & 0 & 0 & 0 & 0 \\
\hline Hand-foot skin reaction & 0 & 0 & 0 & 0 & 1 & 12.5 & 0 & 0 \\
\hline Pruritus & 1 & 12.5 & 0 & 0 & 0 & 0 & 0 & 0 \\
\hline Rash & 3 & 37.5 & 0 & 0 & 0 & 0 & 0 & 0 \\
\hline Face edema & 0 & 0 & 0 & 0 & 0 & 0 & 0 & 0 \\
\hline Limb edema & I & 12.5 & 0 & 0 & 0 & 0 & 0 & 0 \\
\hline
\end{tabular}

\section{Discussion}

In the present study, patients were classified into pathologic responders (grade 2: $50.0 \%$ of all patients: $33.3 \%$ of luminal A type; $0 \%$ of luminal B type; $75.0 \%$ of luminal HER2 type) according to the grade of the tumor. The $\mathrm{pCR}$ rate was
$0 \%$. We recently reported that neoadjuvant FEC followed by weekly paclitaxel and/or trastuzumab induced a high pathologic response in the hormone-negative patients. ${ }^{11}$ However, the present study suggests that neoadjuvant FEC followed by triweekly docetaxel and/or trastuzumab did induce a high pathologic response in luminal HER2 type, but not in luminal A and B types, and did not induce a high pCR rate in the hormone-positive patients. Consistent with this, Rouzier et a ${ }^{15}$ evaluated the gene expression profiles of patients treated with neoadjuvant chemotherapy of FEC followed by weekly paclitaxel and reported that the pCR rate was $45 \%$ for the basal-like and HER2-positive subtypes and $6 \%$ for the luminal tumors.

The conversion of an inoperable breast cancer to an operable one has clinical significance.$^{16} \mathrm{pCR}$ is considered predictive of a long-term outcome in several neoadjuvant trials, ${ }^{17}$ and this finding has been confirmed in two studies. ${ }^{18,19}$ The meta-analysis from the Collaborative Trials in Neoadjuvant Breast $\mathrm{Cancer}^{18}$ included 12 randomized neoadjuvant trials $(\mathrm{n}=13,125)$ and results have shown that individual patients who achieved a $\mathrm{pCR}$ had a more favorable longterm outcome.

In the present study, neoadjuvant FEC followed by triweekly docetaxel and trastuzumab did induce a high pathologic response in luminal HER2 type, but not in luminal A type. Therefore, there is a possibility that adjuvant taxanes provide different benefits for special patient subgroups, especially HER2-positive subgroups. ${ }^{3}$ Moreover, the benefits of adjuvant docetaxel were demonstrated in the whole breast cancer population. ${ }^{19}$ However, further investigation is needed to identify the patients who do not necessarily obtain benefit from docetaxel treatment. Some investigators reported that luminal A tumors should receive endocrine therapy only and should avoid neoadjuvant chemotherapy. ${ }^{20-22}$ However, in breast cancer patients, neoadjuvant chemotherapy may not only induce a pCR, but also change the choice of surgery. In the present study, for luminal A type treated with FEC followed by triweekly docetaxel, although none achieved a pCR, $33 \%$ of luminal A patients were classified into pathologic responders (grades 2 and 3). However, a delay in surgery and hormonal therapy after treating with non-effective neoadjuvant chemotherapy is problematic. ${ }^{23}$ Therefore, further investigations are needed to discuss whether luminal A tumors should receive neoadjuvant chemotherapy. Consistent with this, previous reports ${ }^{24-26}$ suggested that the neoadjuvant treatment for luminal A tumors promoted breast-conserving surgery, and that it was one of the effective treatment options for this groups. 
The pCR rate of the trastuzumab-containing neoadjuvant chemotherapies was reported to be $43 \%-65 \%,{ }^{27}$ because trastuzumab-based therapy for neoadjuvant chemotherapy was a promising alternative for the HER2 subtype. It was suggested that the addition of trastuzumab for neoadjuvant chemotherapy is useful for patients with a HER2-positive tumor. ${ }^{23}$ In the present study, neoadjuvant FEC followed by triweekly docetaxel and/or trastuzumab did induce a high pathologic response in luminal HER2 type. Therefore, incorporation of trastuzumab to the neoadjuvant regimen should be considered in patients with both an ER- and HER2positive tumor.

In the present study, the toxicity profile regarding FEC and triweekly docetaxel and/or trastuzumab administration in our study was generally acceptable (Tables 2 and 3). Consistent with this, it was reported that this regimen is an acceptable neoadjuvant treatment option for hormonepositive breast cancer. ${ }^{28}$

\section{Conclusion}

Recent clinical studies, including this study, have demonstrated that neoadjuvant FEC followed by triweekly docetaxel and/or trastuzumab did induce a high pathologic response in luminal HER2 type, but not in luminal A and B types, and did not induce a high pCR rate in the hormone-positive patients.

\section{Acknowledgment}

We thank Kanako Tanaka for excellent research assistance.

\section{Disclosure}

The authors report no conflict of interest in this work.

\section{References}

1. Wolmark N, Wang J, Mamounas E, Bryant J, Fisher B. Preoperative chemotherapy in patients with operable breast cancer: nine-year results from National Surgical Adjuvant Breast and Bowel Project B-18. J Natl Cancer Inst Monogr. 2001;(30):96-102.

2. Kader YA, El-Nahas T, Sakr A. Adjuvant chemotherapy for luminal A breast cancer: a prospective study comparing two popular chemotherapy regimens. Onco Targets Ther. 2013;6:1073-1077.

3. Park SO, Yoo YB, Kim YH, et al. Effects of combination therapy of docetaxel with selenium on the human breast cancer cell lines MDAMB-231 and MCF-7. Ann Surg Treat Res. 2015;88(2):55-62.

4. Roché H, Fumoleau P, Spielmann M, et al. Sequential adjuvant epirubicin-based and docetaxel chemotherapy for node-positive breast cancer patients: the FNCLCC PACS 01 Trial. J Clin Oncol. 2006; 24(36):5664-5671.

5. Andre F, Broglio K, Roche H, et al. Estrogen receptor expression and efficacy of docetaxel-containing adjuvant chemotherapy in patients with node-positive breast cancer: results from a pooled analysis. J Clin Oncol. 2008;26(16):2636-2643.
6. Mazouni C, Kau SW, Frye D, et al. Inclusion of taxanes, particularly weekly paclitaxel, in preoperative chemotherapy improves pathologic complete response rate in estrogen receptor-positive breast cancers. Ann Oncol. 2007;18(5):874-880.

7. Guarneri V, Broglio K, Kau SW, et al. Prognostic value of pathologic complete response after primary chemotherapy in relation to hormone receptor status and other factors. J Clin Oncol. 2006;24(7): 1037-1044.

8. Sparano JA, Wang M, Martino S, et al. Weekly paclitaxel in the adjuvant treatment of breast cancer. N Engl J Med. 2008;358(16):1663-1671.

9. García-Martínez E, Gil GL, Benito AC, et al. Tumor-infiltrating immune cell profiles and their change after neoadjuvant chemotherapy predict response and prognosis of breast cancer. Breast Cancer Res. 2014; 16(6):488.

10. Ishida T, Kiba T, Takeda M, et al. Phase II study of capecitabine and trastuzumab combination chemotherapy in patients with HER2 overexpressing metastatic breast cancers resistant to both anthracyclines and taxanes. Cancer Chemother Pharmacol. 2009;64(2):361-369.

11. Kiba T, Morii N, Takahashi H, et al. Pathological complete response rate in hormone negative breast cancer patients treated with neoadjuvant FEC and weekly paclitaxel: A case series and review of the literature. Oncol Lett. In press 2015.

12. Yanagawa $M$, Ikemot $K$, Kawauchi $S$, et al. Luminal A and luminal B (HER2 negative) subtypes of breast cancer consist of a mixture of tumors with different genotype. BMC Res Notes. 2012;5:376.

13. Kurosumi M, Akashi-Tanaka S, Akiyama F, et al. Histopathological criteria for assessment of therapeutic response in breast cancer (2007 version). Breast Cancer. 2008;15(1):5-7.

14. Aomatsu N, Yashiro M, Kashiwagi S, et al. CD133 is a useful surrogate marker for predicting chemosensitivity to neoadjuvant chemotherapy in breast cancer. PLoS One. 2012;7(9):e45865.

15. Rouzier R, Perou CM, Symmans WF, et al. Breast cancer molecular subtypes respond differently to preoperative chemotherapy. Clin Cancer Res. 2005;11(16):5678-5685.

16. Papadimitriou K, Ardavanis A, Kountourakis P. Neoadjuvant therapy for locally advanced breast cancer: Focus on chemotherapy and biological targeted treatments' armamentarium. J Thorac Dis. 2010;2(3): 160-170.

17. Kaufmann M, von Minckwitz G, Bear HD, et al. Recommendations from an international expert panel on the use of neoadjuvant (primary) systemic treatment of operable breast cancer: new perspectives 2006. Ann Oncol. 2007;18(12):1927-1934.

18. Cortazar P, Zhang L, Untch M, et al. Meta-analysis results from the collaborative trials in neoadjuvant breast cancer (CTNeoBC). Cancer Res. 2012;72(Suppl):Abstract nr S1-S11.

19. Martin M, Pienkowski T, Mackey J, et al. Adjuvant docetaxel for nodepositive breast cancer. $N$ Engl J Med. 2005;352(22):2302-2313.

20. Parker JS, Mullins M, Cheang MC, et al. Supervised risk predictor of breast cancer based on intrinsic subtypes. J Clin Oncol. 2009;27(8): $1160-1167$.

21. Blows FM, Driver KE, Schmidt MK, et al. Subtyping of breast cancer by immunohistochemistry to investigate a relationship between subtype and short and long term survival: a collaborative analysis of data for 10,159 cases from 12 studies. PLoS Med. 2010;7(5):e1000279.

22. de Ronde JJ, Hannemann J, Halfwerk H, et al. Concordance of clinical and molecular breast cancer subtyping in the context of preoperative chemotherapy response. Breast Cancer Res Treat. 2010;119(1): 119-126.

23. Kim SI, Sohn J, Koo JS, Park SH, Park HS, Park BW. Molecular subtypes and tumor response to neoadjuvant chemotherapy in patients with locally advanced breast cancer. Oncology. 2010;79(5-6):324-330.

24. Kim HS, Park I, Cho HJ, et al. Analysis of the potent prognostic factors in luminal-type breast cancer. J Breast Cancer. 2012;15(4):401-406.

25. Peintinger F, Symmans WF, Gonzalez-Angulo AM, et al. The safety of breast-conserving surgery in patients who achieve a complete pathologic response after neoadjuvant chemotherapy. Cancer. 2006;107(6):1248-1254. 
26. Thomas A, Ohlinger R, Hauschild M, Mustea A, Blohmer JU, Kümmel S. Options and limits of surgery after pre-operative chemotherapy in breast cancer. Anticancer Res. 2006;26(2C):1677-1682.

27. Gianni L, Eiermann W, Semiglazov V, et al. Neoadjuvant chemotherapy with trastuzumab followed by adjuvant trastuzumab versus neoadjuvant chemotherapy alone, in patients with HER2-positive locally advanced breast cancer (the NOAH trial): a randomised controlled superiority trial with a parallel HER2-negative cohort. Lancet. 2010;375(9712):377-384.
28. Hall E, Cameron D, Waters R, et al. Comparison of patient reported quality of life and impact of treatment side effects experienced with a taxane-containing regimen and standard anthracycline based chemotherapy for early breast cancer: 6 year results from the UK TACT trial (CRUK/01/001). Eur J Cancer. 2014;50(14):2375-2389.

\section{Publish your work in this journal}

Breast Cancer: Targets and Therapy is an international, peerreviewed open access journal focusing on breast cancer research, identification of therapeutic targets and the optimal use of preventative and integrated treatment interventions to achieve improved outcomes, enhanced survival and quality of life for the cancer patient.
View the full aims and scopes of this journal here. The manuscript management system is completely online and includes a very quick and fair peer-review system, which is all easy to use. Visit http:// www.dovepress.com/testimonials.php to read real quotes from published authors.

Submit your manuscript here: http://www.dovepress.com/breast-cancer---targets-and-therapy-journal 